$\begin{array}{ll}\text { Fecha de recepción: } & 4 \text { de septiembre de } 2018 \\ \text { Fecha de evaluación: } & 21 \text { de junio de } 2019 \\ \text { Fecha de aprobación: } & 27 \text { de junio de } 2019\end{array}$

\title{
Análisis de la igualdad y la no discriminación en el derecho internacional de los derechos humanos: el caso de los migrantes económicos*
}

\section{María Teresa Palacios-Sanabria* María Lucía Torres-Villarreal ${ }^{* \star *}$}

Para citar este artículo

Palacios, M. y Torres, M. (2019). Análisis de la igualdad y la no discriminación en el derecho internacional de los derechos humanos: el caso de los migrantes económicos. Via luris, (27), 159-179.

\begin{abstract}
RESUMEN
La migración es una realidad global que aumenta cada día, plantea nuevas perspectivas de análisis y es compleja en razón a la multiplicidad de causas y consecuencias que implica; por esto, un sinnúmero de personas abandona sus lugares de origen para establecerse en un territorio de destino, con lo que esto representa en términos sociales, jurídicos y económicos. En el desarrollo del marco jurídico internacional alrededor de la migración, podría pensarse que sus disposiciones resultan aplicables tanto a nacionales como extranjeros y no podría existir antinomia; sin embargo, al hacer un análisis dogmático de algunas de las fuentes normativas e informes que conforman dicho marco, se puede evidenciar que ciertas exclusiones menoscaban expresamente los derechos de los extranjeros y con ello, premisas básicas de los derechos humanos. Este artículo plantea una reflexión desde la aplicación del principio de igualdad y no discriminación para el caso de los migrantes económicos, pues aparentemente se legitima una discriminación por un motivo prohibido, es decir, existe una dificultad con respecto a la igualdad formal, lo que conlleva a la limitación en la práctica de varios derechos y hace más compleja la comprensión de la atribución de los derechos humanos desde su valor intrínseco.
\end{abstract}

* Este producto se enmarca dentro de los proyectos de investigación que sobre el tema de migraciones se adelantan en el Grupo de Investigación en Derechos Humanos de la Facultad de Jurisprudencia de la Universidad del Rosario, dentro de las líneas de derechos emergentes y enfoque diferencial y mecanismos de protección de derechos humanos. En estos proyectos se pueden resaltar: "El derecho a la vida digna en el contexto de la inmigración: los trabajadores migratorios" (tesis doctoral), "Diagnóstico regional de la migración en Colombia con enfoque de derechos humanos (2014-2018)", y "Feminización de la migración venezolana en Colombia: análisis regional con enfoque de derechos humanos (2014-2018)", Bogotá (Colombia).

** Doctora en Derecho y Magíster en Derecho Constitucional de la Universidad de Sevilla, especialista en Derechos Humanos de la ESAP, Abogada de la Universidad del Rosario, profesora de Carrera Académica de la Facultad de Jurisprudencia de la Universidad del Rosario, integrante del Grupo de Investigación en Derechos Humanos, Bogotá, Colombia. ORCID: https:// orcid.org/0000-0002-3266-7411. Correo electrónico de contacto: maria. palacios@urosario.edu.co

*** Magíster en Derechos Humanos y Abogada de la Universidad del Rosario, profesora de Carrera Académica de la Facultad de Jurisprudencia de la Universidad del Rosario, directora del Observatorio Legislativo de la misma universidad, integrante del Grupo de Investigación en Derechos Humanos, Bogotá, Colombia. ORCID: https://orcid.org/0000-0003-0314-3982. Correo electrónico de contacto: maria.torres@urosario.edu.co
DOI: https://doi.org/10.37511/viaiuris.n27a8

Esta obra está bajo una Licencia Creative Commons Atribución-CompartirIgual 4.0 Internacional.

\section{Palabras clave}

Migración, igualdad, no discriminación, derechos

humanos, migrantes económicos, derecho

internacional de los derechos humanos. 


\title{
Analysis of equality and non-discrimination in the international law of human rights: the case of economic migrants
}

\author{
María Teresa Palacios-Sanabria \\ María Lucía Torres-Villarreal
}

\begin{abstract}
Migration is a global reality that increases every day, raises new perspectives of analysis and is complex due to the multiplicity of causes and consequences that it implies. Therefore, countless people leave their places of origin to settle in a destination territory with what this represents in social, legal and economic terms. In the development of the international legal framework around migration, one might think that its provisions are applicable both to nationals and foreigners and there could be no antinomy. However, by making a dogmatic analysis of some of the normative sources and reports that make up this framework, it can be seen that certain exclusions expressly undermine the rights of foreigners and with this, basic premises of human rights. This article raises a reflection from the application of the principle of equality and non-discrimination for the case of economic migrants, because apparently discrimination is legitimized by a prohibited motive and it means a difficulty with respect to formal equality, which entails limitation in the practice of several rights and makes more complex the understanding of the attribution of human rights from its intrinsic value.
\end{abstract}




\title{
Análise da igualdade e não discriminação no direito internacional dos direitos humanos: o caso dos migrantes econômicos
}

\author{
María Teresa Palacios-Sanabria \\ María Lucía Torres-Villarreal
}

\section{RESUMO}

A migração é uma realidade global que aumenta a cada dia, cria novas perspectivas de análise e é complexa devido à multiplicidade de causas e consequências que ela implica; Por esta razão, inúmeras pessoas deixam seus locais de origem para se estabelecerem em um território de destino com o que isso representa em termos sociais, legais e econômicos. No desenvolvimento do arcabouço legal internacional em torno da migração, pode-se pensar que suas disposições são aplicáveis a nacionais e estrangeiros e que não poderia haver antinomia; No entanto, ao fazer uma análise dogmática de algumas das fontes normativas e relatórios que compõem essa estrutura, pode-se evidenciar que certas exclusões minam expressamente os direitos dos estrangeiros e, com isso, as premissas básicas dos direitos humanos. Este artigo levanta uma reflexão a partir da aplicação do princípio da igualdade e da não discriminação no caso dos migrantes econômicos, pois a discriminação é aparentemente legitimada por uma razão proibida, ou seja, existe uma dificuldade em relação à igualdade formal, o que implica limitação na prática de diversos direitos e torna mais complexa a compreensão da atribuição de direitos humanos a partir de seu valor intrínseco. 


\title{
Analyse de l'égalité et de la non-discrimination dans le droit international des droits de l'homme: le cas des migrants économiques
}

\author{
María Teresa Palacios-Sanabria \\ María Lucía Torres-Villarreal
}

\section{RÉSUMÉ}

La migration est une réalité globale qui augmente chaque jour, ouvre de nouvelles perspectives d'analyse et est complexe en raison de la multiplicité des causes et des conséquences qu'elle implique. Pour cette raison, d'innombrables personnes quittent leur lieu d'origine pour s'installer dans un territoire de destination avec ce que cela représente en termes sociaux, juridiques et économiques. Lors de l'élaboration du cadre juridique international relatif aux migrations, on pourrait penser que ses dispositions sont applicables aux nationaux et aux étrangers et qu'il ne peut y avoir d'antinomie; Toutefois, lors d'une analyse dogmatique de certaines des sources normatives et des rapports qui composent ce cadre, il est évident que certaines exclusions portent expressément atteinte aux droits des étrangers et, partant, aux prémisses fondamentales des droits de l'homme. Cet article suscite une réflexion sur l'application du principe d'égalité et de non-discrimination dans le cas des migrants économiques, car la discrimination est apparemment légitimée pour une raison interdite, c'est-à-dire qu'il existe une difficulté en matière d'égalité formelle, qui implique limite la pratique de plusieurs droits et rend plus complexe la compréhension de l'attribution des droits de l'homme à partir de sa valeur intrinsèque. 


\section{INTRODUCCIÓN}

La migración es una realidad de creciente interés mundial; ocupa las agendas de organismos internacionales, de Estados y de la comunidad internacional, pues no solo aumentan las cifras, sino también las causas que la producen, así como la gravedad de las consecuencias en lo que se refiere a los derechos humanos. Esta preocupación condujo a realizar un análisis - en el interior del Grupo de Investigación en Derechos Humanos de la Universidad del Rosario- de algunas de las tendencias actuales que permean el fenómeno migratorio, a fin de estructurar reflexiones que permitan revisar, desde una perspectiva de derechos humanos, el alcance de los flujos migratorios en el mundo moderno.

Según datos reportados por la Organización de las Naciones Unidas (2013), la cifra de migrantes asciende a doscientos cincuenta y ocho millones de personas, lo que equivale al 3,4\% de la población mundial; de este número global, 40,3 millones corresponden a desplazamiento forzado por violencia y conflicto armado, y 26 millones de personas se registran como refugiadas. Por su parte, el Internal Displacement Monitoring Center y el Norwegian Refugee Council (2019) señalan que los desastres naturales y las causas asociadas al cambio climático también reportan unas cifras importantes, toda vez que han generado el desplazamiento de 265,3 millones de personas en un lapso de diez años. De igual forma, el Sistema Continuo de Reportes sobre Migración Internacional en las Américas (Sicremi), expresa en su informe del 2017 que en las Américas se registran 7,2 millones de migrantes, de los cuales el $48 \%$ se moviliza desde Suramérica hacia Estados Unidos y Canadá, un 34\% hacia el interior de los países de Suramérica, y un 18\% hacia Europa, lo que evidencia la dimensión del fenómeno en el continente.

En este orden de ideas, la reflexión principal que se propone en este escrito circunda el tema de la igualdad y, en este sentido, la migración internacional. Dadas sus dimensiones, plantea retos interpretativos en torno a la comprensión y la aplicación de este principio, así como a su correlativo de no discriminación, pues tal y como lo considera Palacios (2012b), si bien se halla previsto en los instrumentos de derecho internacional de los derechos humanos, la realidad evidencia un margen de desprotección de las personas migrantes en función de su situación jurídica y de acceso a los derechos. Así lo ha señalado la Relatoría Especial de Naciones Unidas sobre los derechos humanos de los migrantes en sus informes más recientes, al destacar cómo la forma en que se maneja la migración en los Estados de cara a los grupos con necesidades especiales o el uso de prácticas tales como las devoluciones, los retornos forzosos o las indebidas integraciones sociales, así como no atender la migración con sentido de género, son situaciones - entre muchas otras - que amenazan los derechos de este sector de la población y cuestionan fuertemente las condiciones de igualdad y no discriminación en el acceso a estos.

En este sentido, el presente artículo plantea como pregunta central la siguiente: ¿Cuál es el alcance del principio de igualdad y no discriminación previsto en el derecho internacional de los derechos humanos, aplicable al caso de los inmigrantes económicos? De acuerdo con lo anterior, a manera de hipótesis, este trabajo afirma la existencia de un problema de ausencia de igualdad formal que se ejemplifica de manera evidente en el caso de los trabajadores migratorios, también llamados "inmigrantes", debido a que existen restricciones normativas legitimadas por los tratados, tales como la contenida en el artículo 1.2 de la Convención Internacional para la Eliminación de todas las Formas de Discriminación Racial (CERD), según la cual las diferenciaciones que los Estados podrán hacer entre ciudadanos y no ciudadanos no se consideran una discriminación sino una distinción permitida.

Sobre este aspecto es importante tener presente que la doctrina mayoritaria del derecho internacional de los derechos humanos (por ejemplo, la Comisión de Derecho Internacional (2006), Bluś (2013), Varona Martínez (1994), Villar (2005) y Varlez (1929), asocia la expresión inmigrante a aquella persona que, por motivos económico-laborales, abandona su Estado de origen con el fin de buscar mejores oportunidades en un Estado de destino, lo cual supone la necesidad de un régimen jurídico particular. Por el contrario, desde el concepto amplio y de contenido sociológico, la expresión inmigrante también podría entenderse como la simple salida de un territorio hacia otro. Sobre estos aspectos se hará referencia más adelante.

A efectos de abordar de forma adecuada el desarrollo de la reflexión propuesta, de acuerdo con la pregunta formulada el artículo busca, en primer lugar, analizar algunos elementos de los conceptos 
asociados a los flujos migratorios que se encuentran previstos en las normas del derecho internacional de los derechos humanos y su relación con el elemento de voluntariedad en el acto migratorio; en segundo lugar, estudiar el alcance del principio de igualdad y no discriminación, en cuanto presupuesto contenido en diversos instrumentos internacionales, con el objeto de evidenciar cómo — desde la norma misma- se introducen restricciones en su alcance en lo que a la protección de los extranjeros se refiere, al poner en consideración la igualdad formal y su efecto en la igualdad real y material que predican las normas internacionales y que, desde el mismo plano, legitima distinciones que la cuestionan; en tercer lugar, el análisis se aplica al escenario de los migrantes económicos-laborales con el propósito de poner en evidencia cómo, pese a que existe un tratado de gran contenido en favor de su protección, la interpretación sistemática de otras normas del DIDH ratifica la existencia de normas que autorizan los tratos diferenciados y menoscaban la igualdad, en su calidad de principio, valor y derecho. Finalmente, en el documento se formulan algunas recomendaciones y conclusiones.

\section{METODOLOGÍA}

Para el desarrollo de este escrito se empleó la metodología de investigación dogmática definida por la búsqueda, la compilación y el análisis de fuentes documentales, lo que evidencia la pertinencia de dicho análisis "pues frecuentemente, este constituye el punto de entrada al dominio o ámbito de investigación que se busca abordar e, incluso, es la fuente que origina en muchas ocasiones el propio tema o problema de investigación" (Sandoval, 1996, p. 137). En este sentido, las fuentes documentales fueron la base de la investigación. Se realizó una selección, una revisión y un análisis de doctrina contenida en libros, capítulos de libros y artículos de revistas tanto en español como en inglés. Asimismo, de informes de organizaciones internacionales (informes de relatores especiales, observaciones, recomendaciones) y otros derivados de grupos de análisis de temáticas específicas del orden internacional en los que se hiciera alusión al principio de igualdad y no discriminación, así como a los derechos de la población migrante. De igual forma, se analizaron instrumentos internacionales, como, por ejemplo, tratados y convenios, con el fin de verificar la forma en que se incluyen en este tipo de documentos los temas que se abordan en la investigación y algunas revisiones de jurisprudencia de tribunales internacionales.

Asimismo, la investigación involucra elementos descriptivos, puesto que al analizar el derecho positivo desde la aplicación del principio de igualdad y no discriminación a los inmigrantes se puede este derecho en un sentido restrictivo derivado de la interpretación de las normas internacionales universalmente aceptadas. En este sentido, los elementos de la investigación cualitativa resultan idóneos en la presente investigación, en la medida en que se logra un acercamiento a partir de las fuentes ubicadas y es posible proponer retos y nuevos parámetros de análisis y reflexión a medida que se desarrolla la investigación, lo que permite, de acuerdo con Sandoval (1996), encontrar elementos útiles para los resultados que pretenden hallarse.

De manera preliminar, la investigación contempla una visión humanista. Esto plantea la necesidad de analizar las diferentes aristas de un problema social y la forma como este puede concebirse en razón a su impacto en el contexto mismo, lo cual pone de presente elementos de una investigación cualitativa. Para esto, se parte de la existencia de una realidad dinámica que plantea problemas por atender desde la perspectiva de los derechos humanos y cómo la investigación puede conducir, según Martínez (2011), a una interpretación de esa realidad y a la búsqueda de soluciones a los problemas que se evidencian.

Por último, es pertinente señalar que la metodología propuesta conlleva, como lo expresa Courtis (2006), la posibilidad de establecer aportes que, eventualmente, propicien la creación de estándares internacionales para el manejo de la problemática planteada, a partir de la lectura que se realice del derecho vigente o en esa labor de mejoramiento del ordenamiento jurídico.

\section{RESULTADOS Y DISCUSIÓN}

\section{Reflexiones a partir de los conceptos sobre movimientos de personas: análisis del elemento de voluntariedad}

La migración es un fenómeno humano y demográfico de gran trascendencia para el orden social, económico, cultural y político de un país. Tal como lo señala Gros Espiell (2007), se trata de un suceso: 
[...] complejo y múltiple, que implica y comprende elementos individuales y colectivos, que responde y es la consecuencia de diversas causas que se suman y entremezclan en distinta intensidad, según los diferentes momentos históricos y los diversos lugares geográficos y situaciones en que ocurre. (p. 42)

Si bien la movilización de personas a lo largo de la historia ha sido una constante, el concepto es relativamente reciente si se valora desde la misma ocurrencia de este hecho humano y desde la perspectiva de otros conceptos que existen en el derecho internacional público. Así se afirma en un estudio publicado por la Academia de Derecho Internacional, el cual señala: “La migración es un neologismo, y que su existencia constituye la evidencia histórica de la evolución propia del lenguaje, el cual ha sido influido por el desarrollo internacional, y que se concreta posteriormente en una norma jurídica" (Varlez, 1929, p. 173). De igual forma, si bien no existe una definición universalmente aceptada de lo que se entiende por migración, señala la Organización Internacional para las Migraciones (OIM) que la migración se entiende como el "movimiento de población hacia el territorio de otro Estado o dentro del mismo, que abarca todo tránsito de personas sea cual fuere su tamaño, su composición o sus causas; incluye migración de refugiados, personas desplazadas, personas desarraigadas, migrantes económicos" (2006, p. 38).

La noción anterior supone la movilización de las personas de manera genérica y sin que medie ningún calificativo; en esta primera aproximación, no se hace explícito si esto es voluntario, forzado o si existe otro denominador para la movilización. Esto quiere decir, que se alude a la migración en sentido amplio, la cual admite muchas posturas sobre el acto migratorio y contempla necesariamente dos situaciones: la emigración, es decir, la salida de los individuos o el abandono por parte de los mismos de un lugar, ya sea un país o una región y la inmigración, esto es, el ingreso de los individuos en un territorio determinado. Lo anterior, al considerar el supuesto de que la migración es el género y la emigración y la inmigración las especies que la componen o sus partes fundamentales. (Palacios, 2012b, p. 35)

De acuerdo con la OIM (2006), entre los tipos de migración es necesario tener presente el elemento de la voluntariedad para establecer la causa de la migración y, en consecuencia, el estatuto jurídico aplicable. Se pueden configurar diferentes escenarios: por una parte, la migración forzada, que se trata de aquella que puede desarrollarse en un contexto interno o externo y describe el movimiento de personas, en el cual se puede observar coacción y, con esto, ausencia de voluntariedad, lo que incluye la amenaza a la vida y la subsistencia, bien sea por causas naturales o humanas o bien derivadas de los conflictos armados.

Respecto de la migración forzada interna, señala Varlez (1929) en el estudio preparado para la Academia de Derecho Internacional, existen varios tipos de migraciones. Una de ellas es, de acuerdo con Buergenthal, Grossman y Nikken, (1990), la que se caracteriza por la ocurrencia de movilizaciones en los campos, el abandono de territorios o el desplazamiento a causa del desarrollo de actividades empresariales en aras de explotar los recursos naturales, entre otros aspectos. En el escenario de los movimientos internacionales con motivos forzados, más conocidos como "refugio"1, se consolida la migración cuando en la persona existen:

Fundados temores de ser perseguida por motivos de raza, religión, nacionalidad, pertenencia a determinado grupo social u opiniones políticas, se encuentre fuera del país de su nacionalidad y no pueda o, a causa de dichos temores, no quiera acogerse a la protección de tal país; o que, careciendo de nacionalidad y hallándose, a consecuencia de tales acontecimientos, fuera del país donde antes tuviera su residencia habitual, no pueda o, a causa de dichos temores, no quiera. (Convención sobre el Estatuto de los Refugiados, 1951, art. 1.2)

Por otra parte, se encuentran las migraciones voluntarias, hecho desde el cual cambia la perspectiva, toda vez que, según Błuś (2013), en estas se presume que los individuos no son víctimas de coacción alguna para salir de sus países, sino que, de manera voluntaria, deciden hacerlo por múltiples razones;

\footnotetext{
1 A manera de explicación, es importante tener presente que, dadas las coyunturas históricas de América Latina, se reconoce la existencia de la figura del asilo territorial y diplomático. Sin embargo, se considera que el refugio, en su sentido universal, presenta mayores ventajas desde su flexibilidad conceptual para dar protección a un mayor número de personas víctimas de las persecuciones que no solo se limiten a motivos de opinión política (Grütters, 2011, pp. 241-243).
} 
entre estas se encuentran las económicas o denominadas "migraciones laborales".

En la práctica, la transparencia conceptual se pone en tela de juicio, pues tal y como lo manifiesta Olesti Rayo (2005, p. 943), “los planteamientos para fundamentar las migraciones por razones económicas son diversos, y demuestran que estamos ante una manifestación social compleja". Una de las principales dificultades que ofrece la realidad migratoria es el motivo o causa por el que se decide abandonar el Estado de origen, lo cual comporta motivaciones con connotaciones económicas, en algunas circunstancias moderadas o en otras extremas, pues la finalidad principal es la búsqueda de un mejor trabajo que permita aumentar las condiciones de existencia o, por lo menos, aproximarse a un nivel de vida adecuado, derecho previsto en el artículo 25 de la Declaración Universal de los Derechos Humanos de 1948 (en adelante DUDH) e interpretado por la Observación General N. ${ }^{\circ} 15$ del Comité de Derechos Humanos, relativa a la situación de los extranjeros con arreglo al pacto.

Además de la motivación particular para migrar, influye enormemente en esta decisión el contexto socioeconómico en el que se encuentra la persona. Sobre esto, en el informe de la Relatora Especial sobre los derechos humanos de los migrantes ${ }^{2}$ correspondiente al 2005, se lee:

Se percibe la emigración como la única solución frente al desempleo y la pobreza. El crecimiento económico que han experimentado algunos países en los últimos años no se ha reflejado aún en una mejora significativa del mercado laboral que permita la inserción de los jóvenes en el trabajo y la reducción del desempleo y la informalidad. Además, continúan existiendo amplias zonas en donde el olvido social y el desinterés político serían evidentes, lo que obliga a sus poblaciones a buscar trabajo en los países vecinos como estrategia de subsistencia. (Asamblea General de Naciones Unidas, 2005, párr. 3)

2 Señala la misma Relatora que "En la mayor parte de los casos, los trabajadores y trabajadoras salen de sus países de origen solos. Este es un factor de riesgo de desintegración familiar. Los cabezas de familia emigran para sobrevivir dignamente y enviar recursos a los suyos" (Asamblea General de Naciones Unidas, 2005, párr. 50).
Asimismo, al analizar las causas de la migración, la Asamblea General de las Naciones Unidas (2001) señala:

El movimiento de personas dentro y fuera de las fronteras nacionales es el resultado entre otras de la extrema pobreza, la discriminación racial, los conflictos armados internos, la falta de oportunidades, la discriminación contra las mujeres y la reunificación familiar. (párr. 18)

Sobre esto conviene tener presente una de las preocupaciones expuestas por el Relator Especial sobre el derecho a la alimentación (Asamblea General de las Naciones Unidas, 2008), pues acuña el concepto de refugiados del hambre, al entender por tales "Ios más excluidos y discriminados las personas que huyen del hambre y de graves violaciones del derecho a la alimentación", lo que fácilmente podría contrastarse con lo sucedido a los migrantes económicos que huyen de situaciones de miseria extrema, tal y como lo expone De Lucas (2015) al referirse a los náufragos migrantes en las costas del Mediterráneo y a la situación en la frontera colombo-venezolana, hechos que han sido catalogados por la Organización de Naciones Unidas (2018) como un asunto de interés para la comunidad internacional, en la que se deben adoptar acciones robustas en razón a que puede desencadenarse una crisis humanitaria.

Ahora bien, si esto llega a suceder dentro de las fronteras de un Estado y se trata de sus nacionales, podría configurarse como un desplazamiento interno, toda vez que quienes lo padecen, tras el traslado forzoso, experimentan sucesivas vulneraciones a sus derechos. Tal como lo señala el profesor Cançado Trindade (2003) al referirse a este mismo punto, las migraciones y los desplazamientos pueden caracterizarse por condiciones de vida desiguales entre el lugar de origen y el de destino de los migrantes. Es ilustrativo sobre este tema el caso colombiano, toda vez que la condición de desplazado (Ley 387 de 1997) se atribuye solo en el marco del conflicto armado y la violencia generalizada, y no tiene en consideración las causales de movilización originadas en la pobreza, el hambre y la desigualdad social.

Pese a lo anterior, la doctrina del derecho internacional de los derechos humanos ha desarrollado conceptos restringidos sobre la migración, para Palacios (2012), vinculados a la voluntaria y por motivos económico-laborales, desconociéndose importantes apreciaciones como, por ejemplo, 
la puesta de presente por Naciones Unidas en el marco del Diálogo de alto nivel sobre la migración internacional y el desarrollo (2006, párr. 8,16), al señalar que algunos de los motivos principales por los cuales las personas deciden migrar son "la pobreza, los conflictos y las violaciones a los derechos humanos", lo que en últimas cuestiona fuertemente el elemento de voluntariedad.

Conforme con lo expresado por De Lucas (2002), esta visión segmentada de las causas de la migración ha ocasionado que del tratamiento dado a estas personas, se excluyan por completo los motivos humanitarios y se presuma que en todos los casos los migrantes abandonan sus Estados de origen por mera voluntariedad, lo que acarrea como consecuencia una reglamentación excluyente, protectora de fronteras, defensora a ultranza de la soberanía de los Estados y represiva, que deshumaniza la migración y desconoce que las personas huyen de las críticas condiciones de vida que tienen sus raíces en la desigualdad, no solo entre las personas, sino entre los Estados.

Otro de los efectos adversos que se presenta en la aplicación de las normas que dan tratamiento a los migrantes de una forma fragmentada radica en que no es posible hacer extensiva la figura del refugio y la protección derivada de esta para aquellas situaciones que en el marco de la migración cuestionan la voluntariedad y obedecen a motivos de pobreza extrema $u$ otras situaciones derivadas de la desigualdad estructural; en su lugar, será la Convención internacional sobre la protección de los derechos de todos los trabajadores migratorios y de sus familiares (en adelante CTMF) la normativa sectorial aplicable, la cual, a pesar de ser un importante y completo instrumento, no ha sido a la fecha ratificada por ningún Estado considerado como desarrollado y de destino por parte de los inmigrantes, sino únicamente por Estados de origen, lo que restringe aún más la urgente e inminente protección integral de los migrantes, situación que evidencia Chetail (2013).

\section{La protección de los migrantes: iuna cuestión de igualdad?}

En este apartado se abordan reflexiones en torno a la protección de los migrantes en el ámbito universal y regional, a partir de algunos tratados internacionales y desde la perspectiva de la efectiva aplicación de un pilar esencial del derecho internacional de los derechos humanos, como lo es el principio de igualdad y no discriminación, con el fin de evidenciar el problema de igualdad formal derivado de la norma misma y que es legitimado por la comunidad internacional y se reproduce en las normas internas. Así, por ejemplo, ocurre en el caso colombiano, dado que si bien se predica la igualdad de derechos entre nacionales y extranjeros en el artículo 100 de la Constitución, de todas formas se permiten restricciones en función de lo establecido por las leyes. Lo anterior, con el objetivo de plantear los presupuestos para un abordaje posterior de la situación de los migrantes por motivos económicolaborales, según la CTMF.

A fin de abordar este apartado, es necesario empezar por conceptualizar sobre el principio de igualdad y no discriminación, de tal forma que luego permita comprender el eje central que se plantea en este escrito, relativo a la existencia de una discriminación fundada en un motivo prohibido que ha sido legitimada por los propios instrumentos internacionales de protección de derechos humanos y deriva en la imposibilidad de predicar la existencia de una igualdad formal que sea aplicable a los trabajadores migrantes, lo que, por una parte, menoscaba el marco de los derechos y, por otra, resulta contradictorio con el espíritu mismo del gran cuerpo normativo que conforma el derecho internacional de los derechos humanos.

El principio de igualdad y no discriminación ha estado presente desde los orígenes del proceso de internacionalización de los derechos humanos, tal como consta en el preámbulo de la Carta de la Organización de las Naciones Unidas al proclamar la igualdad de derechos de hombres y mujeres. De lo anterior, se colige:

Que todas las personas son titulares de las garantías por el hecho mismo de pertenecer a la especie humana, en razón de ello, la igualdad y no discriminación conforma casi un binomio inseparable con la dignidad de la persona humana. (Palacios, 2012, p. 79)

En el mismo sentido, el profesor Fernández De Casadevante Romaní (2007) precisa que la DUDH señala los derechos y libertades fundamentales de las personas, sin discriminación alguna, lo que sin duda representa un progreso, aunque no absoluto en materia de igualdad (Cassese, 1993). 
La importancia de la DuDH es indudable, dado que constituye el primer instrumento jurídico mundial "que recoge un conjunto de principios en los que se consagran los derechos y libertades fundamentales del ser humano, reconocidos por la Comunidad Internacional" (Villán, 2001, p. 51) y fundamentados en la igualdad y otros principios esenciales para el género humano. Lo consagrado en el preámbulo de la misma declaración permite sostener que todas las personas, por el solo hecho de pertenecer a la especie humana, son titulares de los derechos humanos y estos no se reconocen de cualquier modo, sino en un plano de igualdad de condiciones. Al analizar otras disposiciones contenidas en la DUDH, puede reconocerse la incorporación de forma expresa de la igualdad como principio fundamental, al poner de presente la existencia de derechos tales como la igualdad ante la ley (art. 7), las garantías propias del debido proceso (art. 10), el derecho a la familia (art. 16), el acceso a la función pública (art. 21), la igualdad en materia de salario (art. 2 3.2), la protección de los derechos sociales de los niños (art. 25.2), o el acceso a estudios superiores (art. 26.1), entre otros que, si bien no están de manera explícita referidos a la igualdad, de su contenido se colige su esencia al ser propuestos en un sentido positivo, esto es, a favor de "toda persona" o "todo individuo" ${ }^{3}$, o bien en sentido negativo al utilizar el término nadie, es decir, nadie puede ser objeto de tratos prohibidos ${ }^{4}$.

En este punto resulta conveniente analizar el principio de no distinción, el cual se encuentra explícito también en varios instrumentos internacionales y determina si tiene la misma dimensión del principio de no discriminación.

En este sentido, por discriminación se entiende un trato prohibido, proscrito por el derecho internacional de los derechos humanos y que obedece a las exclusiones, a los privilegios o al menoscabo del ejercicio de los derechos por motivos de raza, sexo, posición económica o política u origen nacional, entre otros. Además de esto, es un trato no objetivo, ni

3 Véanse los arts. 1, 2, 3, 6, 7, 8, 10, 11.1, 13, 14, 15.1, 16, 17.1, $18,19,20.1,22,23,24,25,26,27,28$ у 29.

4 Arts. 4, 5, 9, 11.2, 12, 15.2, 17.2 y 20.2. La Carta Internacional de Derechos Humanos, esto es, la DUDH, el Pacto Internacional de Derechos Civiles y Políticos y el Pacto Internacional de Derechos Económicos, Sociales y Culturales, más sus protocolos adicionales, también hacen alusión explícita al principio de igualdad. Dichos pactos cuentan con preámbulos comunes que toman elementos de la DUDH y, en este sentido, se refieren a los derechos iguales e inalienables de las personas. razonable e incompatible con una sociedad democrática. Por su parte, la distinción es, para Palacios (2012), lo contrario a la discriminación, y supone una diferencia de trato permitida en el DIH (por consiguiente, es objetiva, razonable y compatible con una sociedad democrática).

La Carta de la ONU (1945, Art. 55.c) señala, al igual que la DUDH, en su artículo 2:

Con el propósito de crear las condiciones de estabilidad y bienestar necesarias para las relaciones pacíficas y amistosas entre las naciones, basadas en el respeto al principio de la igualdad de derechos y al de la libre determinación de los pueblos, la Organización promoverá [...] el respeto universal a los derechos humanos y a las libertades fundamentales de todos, sin hacer distinción por motivos de raza, sexo, idioma o religión, y la efectividad de tales derechos y libertades. (ONU, 26 de junio de 1945, art. 55. c.) (DUDH, art 2.)

Lo anterior evidencia el desarrollo evolutivo o progresivo del principio de no distinción y denota también la pretensión de universalización de los derechos humanos; vale resaltar que, en estos dos instrumentos citados, la no distinción y la no discriminación aluden a una conducta prohibida que deben evitar los Estados y, en consecuencia, se tratan como sinónimos. En este punto es pertinente referirse a lo que se ha entendido por discriminación formal. Según el Comité de Derechos Económicos, Sociales y Culturales, en la Observación General N. ${ }^{\circ} 20$ (2009), debe entenderse por esta aquella que proviene de las normas del Estado y señala cómo, "para erradicar la discriminación formal es preciso asegurar que la Constitución, las leyes y las políticas de un Estado no discriminen por ninguno de los motivos prohibidos" (pár. 8.a), como lo es el origen nacional. De igual manera, señala cómo, a fin de que en la práctica esto sea una realidad, debe prestarse atención a los grupos históricamente discriminados o vulnerables, al adoptar las medidas necesarias "para prevenir, reducir y eliminar las condiciones y actitudes que generan o perpetúan la discriminación sustantiva o de facto" (pár. 8.b).

A pesar de lo anterior, al profundizar en el análisis de los tratados sectoriales de derechos humanos, tales como la Convención Internacional para la Eliminación de todas las formas de Discriminación Racial (en adelante CERD) y la Convención sobre la 
Eliminación de todas las formas de Discriminación contra la Mujer (en adelante CEDAW, por sus siglas en inglés), entran a definir de manera textual lo que debe entenderse por discriminación; en su lugar, los órganos de los tratados, al interpretar dichas normas, sugieren que en efecto existe una diferencia entre la no distinción y la no discriminación, al entender la primera como un trato legítimo que le es dable a los Estados por motivos objetivos, razonables y propios de una sociedad democrática, en tanto que la segunda constituye un trato prohibido, pues no obedece a motivos objetivos ni razonables y son lejanos a una sociedad democrática. Esto ha sido reiterado en la jurisprudencia de los tribunales regionales:

De acuerdo con lo anterior, para la CERD (1965) se entiende por discriminación (definición que es empleada por los diferentes comités de Naciones Unidas):

[...] toda distinción, exclusión, restricción o preferencia basada en motivos de raza, color, linaje u origen nacional o étnico que tenga por objeto o por resultado anular o menoscabar el reconocimiento, goce o ejercicio, en condiciones de igualdad, de los derechos humanos y libertades fundamentales en las esferas política, económica, social, cultural o en cualquier otra esfera de la vida pública. (Art.1.1)

De una primera lectura pareciera inferirse que la definición de prohibición de discriminación es aplicable a las personas extranjeras; sin embargo, el artículo 1.2 de la CERD (1965) excluye de manera expresa la aplicación de la anterior disposición a los no ciudadanos al señalar: "No se aplicará a las distinciones, exclusiones, restricciones o preferencias que haga un Estado parte en la citada Convención entre ciudadanos y no ciudadanos" (art. 1.2). De lo anterior surge la reflexión en torno a si la propia CERD legitima una discriminación por un motivo prohibido, lo que significaría que los extranjeros, incluidos los trabajadores migrantes, podrán ser sujetos de distinciones al interior de un Estado y esto no podría ser interpretado como una discriminación que transgreda las normas internacionales y menoscabe el acceso a los derechos en condiciones de igualdad.

Con el propósito de hacer una correcta interpretación de la CERD en el artículo referido, el Comité para la
Eliminación de la Discriminación Racial ha expresado en la Recomendación General N. ${ }^{\circ}$ Xxx (2005):

Se prevé la posibilidad de distinguir entre ciudadanos y no ciudadanos. El párrafo 3 del artículo 1 declara que las disposiciones legales de los Estados partes sobre nacionalidad, ciudadanía o naturalización no podrán establecer discriminación contra ninguna nacionalidad en particular. (párr. 1)

\section{$[\ldots]$}

Debe interpretarse que en el párrafo 2 del artículo 1 se trata de evitar socavar la prohibición básica de la discriminación; por consiguiente, no debe interpretarse que redunda en modo alguno en detrimento de los derechos y libertades reconocidos y enunciados en particular en la Declaración Universal de Derechos Humanos, el Pacto Internacional de Derechos Económicos, Sociales y Culturales y el Pacto Internacional de Derechos Civiles y Políticos. (párr. 2)

No obstante, las distinciones que se producen entre los ciudadanos y los no ciudadanos, según el comité citado, se ubican dentro del marco admisible por el derecho internacional y la diferencia de trato entre los nacionales y los extranjeros:

Basada en la ciudadanía o en la condición de inmigrante constituirá discriminación si los criterios para establecer esa diferencia, juzgados a la luz de los objetivos y propósitos de la Convención, no se aplican para alcanzar un objetivo legítimo y no son proporcionales al logro de ese fin. (2005, párr. 4)

Como puede observarse, la definición dada por la Convención limita su aplicación a un colectivo de personas que han sido tradicionalmente discriminadas, es decir, a los extranjeros, toda vez que pese al reconocimiento del principio a la igualdad como pilar fundamental de los instrumentos y tratados internacionales, el avance en la reivindicación de los derechos de estas personas se ha producido a través de un lento y complejo proceso de equiparación restringido ${ }^{5}$ que, de todos modos, incurre en la

5 Término acuñado por algunos representantes de la doctrina internacionalista, tales como J. Bonet Pérez (2003), F. Gómez Isa (2009) y J. Pureza (2004). Asimismo, Juste Ruiz (2005) y J. F. Mariño Menéndez (1996). 
transgresión de la prohibición de discriminación por un motivo prohibido (este es, el origen nacional).

De igual manera, tanto la interpretación dada por el Comité para la Eliminación de la Discriminación Racial como la emitida por otros órganos de los tratados ${ }^{6}$ podría llevar a cuestionar la existencia de una discriminación por motivos de origen nacional, así como a afirmar que lo que existe es una legitimación de la discriminación por este motivo aún aceptada por el derecho internacional, a efectos de no invadir las esferas que de forma tan celosa guardan los Estados dentro de su margen de discrecionalidad, tal como ocurre con la política migratoria y los asuntos que la rodean. Podría considerarse, entonces, que en las normas internacionales todavía existen limitaciones que plantean zonas grises en cuanto a la discriminación se refiere, pues se evidencian dificultades para el acceso a los derechos por parte de los extranjeros, en especial el derecho de entrada y de libre circulación por el territorio de un Estado, así como en el tema de los derechos políticos, lo que pone de presente la inexistencia de igualdad formal para los migrantes.

La exclusión expresa de estas personas del campo de aplicación personal de la Convención, según Carrillo (2001), se sustenta en la defensa y el respeto por la soberanía de los Estados, lo cual tiene incidencia directa en la estructuración de su política migratoria, toda vez que no compete al derecho internacional entrar a regular aspectos de esta envergadura. Adicional a lo anterior, la jurisprudencia internacional ha marcado una estricta diferencia entre lo que se debe considerar como una distinción, legítima y compatible con el derecho internacional de los derechos humanos, y lo que es una discriminación, que tal y como se ha señalado es prohibida y consta de unos motivos específicos, aunque no taxativos.

Según la jurisprudencia internacional, las distinciones son tratos diferenciados compatibles con el derecho internacional de los derechos humanos. Como ejemplo ilustrativo de ellos puede referirse el Tribunal Europeo de Derechos Humanos, el cual ha sostenido en el caso Gaygusuz c. Austria (1996), al pronunciarse acerca de la procedencia de un

6 Para ilustrar de una mejor manera esta afirmación, puede consultarse la Observación General N. ${ }^{\circ} 15$ del Comité de Derecho Humanos. También es preciso integrarla con lo que se ha puesto de presente en la Observación General N. ${ }^{\circ} 18$ del mismo Comité (pár.13). trato diferencial del que eran objeto los nacionales de terceros Estados a la hora de obtener el reconocimiento de ciertas prestaciones asistenciales, que dicha conducta diferenciada entre nacionales austriacos y extranjeros a efectos del reconocimiento de esta prestación de la que el demandante era víctima, no está basada en ninguna justificación objetiva ni razonable $y$, en consecuencia, constituía una discriminación. Asimismo, la Comisión Europea contra el Racismo y la Intolerancia (2002) ha determinado que, a diferencia de la distinción, por discriminación se entenderá:

Todo trato diferenciado por motivos de raza, color, idioma, religión, nacionalidad, u origen nacional o étnico, que no tenga una justificación objetiva y razonable. El trato diferenciado no tiene una justificación objetiva y razonable si no persigue un objetivo legítimo o si no existe una relación razonable de proporcionalidad entre los medios empleados y el objetivo que se pretende alcanzar. (párr. 1.b)

En el escenario interamericano, las normas predican valores similares; así, la Declaración Americana de Derechos y Deberes del Hombre de 1948 (en adelante $\mathrm{DADH}$ ) proclama en su preámbulo la igualdad de los derechos reconocidos en su texto, al señalar: "Todos los hombres nacen libres e iguales en dignidad y derechos" (pár. 1). Por su parte, la Convención Americana sobre Derechos Humanos (en adelante $\mathrm{CADH})$ prevé dicho reconocimiento en los mismos términos en que fue formulado por la DADH, es decir, al incluir, junto con el reconocimiento del derecho a la igualdad, la prohibición general de discriminación:

Los Estados partes en esta Convención se comprometen a respetar los derechos y libertades reconocidos en ella y a garantizar su libre y pleno ejercicio a toda persona que esté sujeta a su jurisdicción, sin discriminación alguna por motivos de raza, color, sexo, idioma, religión, opiniones políticas o de cualquier otra índole, origen nacional o social, posición económica, nacimiento o cualquier otra condición social. (DADH, 1948, art.1.1)

Adicional a esto agrega que, "para los efectos de esta Convención, persona es todo ser humano" (art.1.2).

Por su parte, la Corte Interamericana de Derechos Humanos (en adelante Corte IDH), también se ha manifestado sobre este aspecto, y así considera que, 
a fin de que las distinciones sean legítimas, deben obedecer a una justificación objetiva y razonable compatible con el debido respeto de los derechos humanos y la aplicación del principio pro persona. Desde las primeras opiniones consultivas, la Corte IDH se pronuncia sobre la igualdad y no discriminación. De esta manera, en la N. ${ }^{\circ} 4$ de 1984, en la que se aclara el alcance de la $\mathrm{CADH}$, se precisa la diferencia conceptual entre lo que significa la "distinción" y lo que implica la "discriminación", entendiendo el primero como lo admisible, por ser razonable, proporcional y objetivo, y la discriminación como lo inadmisible, empelándose ese término para referirse "a toda exclusión, restricción o privilegio que no sea objetivo y razonable, que redunde en detrimento de los derechos humanos" (Corte IDH, 1984, pár. 84). Como puede notarse, no se distancia mucho de lo que ya los tratados sectoriales de las Naciones Unidas habían reconocido al respecto.

Sobre la aplicación específica de estos principios a los extranjeros y más concretamente a los trabajadores migrantes, la Opinión Consultiva N. ${ }^{\circ} 18$ de 2003 aporta elementos esenciales para este estudio. Señala la Corte IDH cómo para que las distinciones sean legítimas deberán obedecer a una justificación objetiva y razonable, ser compatibles con el debido respeto de los derechos humanos y conformes a la aplicación del principio de la norma que mejor proteja a la persona. Agrega, además, que la limitación en el ejercicio de determinados derechos políticos en atención a la nacionalidad o ciudadanía no es contraria al principio de no discriminación.

La apreciación de la Corte IDH, según las palabras del profesor Chueca Sancho (2003, p. 305), "ofrece mayor interés, porque la prohibición de discriminar no implica igualitarismo absoluto sino, como suele afirmarse, implica tratar de modo igual a los iguales y de modo desigual a los desiguales". Valdría la pena preguntarse, frente a la opinión del autor, si los extranjeros y los inmigrantes son desiguales por sí mismos. En respuesta a esto, resultaría coherente afirmar que, en función de las limitaciones admitidas por el DIDH, tal y como se ha señalado en este texto, esta sería una cuestión sobre la que no se admite debate en torno a la probabilidad de que exista una igualdad plena que desborde la nacionalidad y atienda a la propia condición humana. En ese orden de cosas, sería pertinente analizar hasta qué punto existe, en el marco de la protección internacional, igualdad formal y material para el acceso a los derechos de este grupo de personas.
Según lo propuesto por Chueca Sancho (2003), lo anterior implica el logro de la igualdad material al superar así la simple igualdad formal, la cual en ocasiones olvida la verdadera condición de las personas, a quienes sus derechos no se satisfacen con la mera existencia de la norma jurídica, sino con la adopción de medidas tendientes a eliminar las diferencias existentes. En lenguaje de la Corte, dichas acciones suponen "adoptar medidas positivas para revertir o cambiar situaciones discriminatorias existentes en sus sociedades, en perjuicio de determinado grupo de personas" (Corte Interamericana de Derechos Humanos, 2003, pár. 104).

En la comentada Opinión Consultiva N. 18 (2003), el principio de igualdad y no discriminación se considera una norma de ius cogens:

Toda vez que sobre ella descansa todo el andamiaje jurídico del orden público nacional e internacional y es un principio fundamental que permea todo ordenamiento jurídico. Hoy día no se admite ningún acto jurídico que entre en conflicto con dicho principio fundamental, no se admiten tratos discriminatorios en perjuicio de ninguna persona, por motivos de género, raza, color, idioma, religión o convicción, opinión política o de otra índole, origen nacional, étnico o social, nacionalidad, edad, situación económica, patrimonio, estado civil, nacimiento o cualquier otra condición. (párr. 101)

Pese a lo anterior, nunca quiso ser una pretensión de la Corte IDH predicar una política de puertas abiertas a favor de la inmigración; de hecho, el hehcho de que los inmigrantes deban recibir un trato digno al interior del Estado de destino no significa que no se puedan iniciar acciones en caso de que se encuentren en situación de irregularidad o de que exista una transgresión del ordenamiento jurídico, ya que es legítimo para "el Estado otorgar un trato distinto a los migrantes documentados con respecto de los migrantes indocumentados, o entre migrantes y nacionales, siempre y cuando este trato diferencial sea razonable, objetivo, proporcional, y no lesione los derechos humanos" (Corte IDH, 2003, párr. 118 y 119).

De lo expresado por la Corte IDH se puede extraer una conclusión, según la cual es claro que los tratos diferenciados son admisibles por el ordenamiento interamericano y estos podrán definir el marco de los derechos de los inmigrantes según su situación 
jurídica, de tal modo que dentro de la potestad soberana de cada país podrán incorporarse beneficios para aquellos que sean documentados y podrán proceder las restricciones a los derechos por vía legal, de aquellos que se no cuenten con la documentación en regla para ingresar, transitar y permanecer dentro de la jurisdicción de un país de "acogida"7.

\section{Análisis de la CTMF: ¿un avance hacia el pleno derecho a la igualdad?}

El artículo 1.1 de la CTMF (1990) dispone que esta:

será aplicable, salvo cuando en ella se disponga otra cosa, a todos los trabajadores migratorios y a sus familiares sin distinción alguna por motivos de sexo, raza, color, idioma, religión o convicción, opinión política o de otra índole, origen nacional, étnico o social, nacionalidad, edad, situación económica, patrimonio, estado civil, nacimiento o cualquier otra condición. (art. 1.1)

Lo anterior evidencia que el principio de no discriminación es el "que domina la Convención" (Kariyawasam, 2006, p. 19), y, a pesar de que señala que es susceptible de ser aplicado a todos los trabajadores migratorios y sus familias, en el mismo contenido se referencian los motivos que sustentan la prohibición de la discriminación y se consideran las eventuales distinciones, lo cual se suscita al revisar el artículo 5으, que introduce una distinción entre trabajadores migratorios en condición de regularidad y aquellos que están en la situación jurídica contraria.

Debe precisarse que los principios de igualdad y no discriminación en la CTMF reiteran las disposiciones aplicables a los extranjeros en los demás instrumentos internacionales analizados. Tales principios, en la CTMF, son el "punto de partida axiológico y jurídicopolítico del desarrollo del DIDH, lo cual se evidencia en lo previsto en su artículo 1.1" (Bonet, 2003, p. 95), lo que lo constituye en un importante aporte al dar claridad al estatuto jurídico aplicable a los trabajadores migrantes, pues en los demás instrumentos internacionales las disposiciones aplicables a los extranjeros se tornan vagas, generales y abstractas.

7 Debe anotarse que la expresión país de acogida es sinónima de país de destino, y cómo en este caso no implica que el país acepte $u$ otorgue permiso a la persona.
La CTMF, al parecer, progresa hacia la igualdad entre los nacionales y los extranjeros, y esto puede constatarse en el reconocimiento general de algunos derechos que no obedecen al condicionante de la situación jurídica de regularidad o de irregularidad de las personas. Dichas disposiciones están reconocidas en el artículo 1.1 y en los artículos del 8 al 33, esto es, la tercera sección del tratado. Por su parte, en el artículo $7^{\circ}$ se reconoce el principio de no discriminación de manera específica, al prescribir:

Los Estados partes se comprometerán, de conformidad con los instrumentos internacionales sobre derechos humanos, a respetar y asegurar a todos los trabajadores migratorios y sus familiares que se hallen dentro de su territorio o sometidos a su jurisdicción, los derechos previstos en la presente Convención, sin distinción alguna por motivos de sexo, raza, color, idioma, religión o convicción, opinión política o de otra índole, origen nacional, étnico o social, nacionalidad, edad, situación económica, patrimonio, estado civil, nacimiento o cualquier otra condición. (CTMF, 1990, art.7)

La referida disposición normativa confirma que todos los tratados internacionales adoptados en el seno de las Naciones Unidas deberían aplicarse a todas las personas, lo que incluye también a los extranjeros. Como lo manifiesta Vanheule (2009), a pesar de que la mayoría de los tratados en vigor hasta inicios de la década de los noventa eran aplicables a todas las personas, incluidas las extranjeras, dada su redacción se hizo necesario adoptar uno sectorial o específico que fortaleciera la protección de estas personas. Por otra parte, la definición de discriminación prevista en la CMTF retoma los parámetros de la CERD y la CEDAW, y es más explícita al incluir la expresión de "cualquier otra condición", lo cual significa que los motivos prohibidos para discriminar son dinámicos y no se puede hablar de una lista taxativa en este sentido.

Antes de continuar con el análisis de los derechos que podrían considerarse un progreso en materia de protección, es necesario puntualizar sobre el campo de aplicación personal del tratado, pues debido a la rigurosidad con la que se manejan los conceptos jurídicos asociados a los movimientos de personas, una gran mayoría de extranjeros que ingresan al territorio de un Estado de destino pueden considerarse trabajadores migrantes; en tal supuesto, pueden estar ubicadas todas aquellas 
personas que cruzan una frontera internacional y no pueden calificarse como refugiados por no ajustarse a los estrictos motivos definidos por la Convención de 1951 y su protocolo adicional. En este orden de cosas, el desarrollo de cualquier actividad económica de subsistencia formal o informal daría paso a la aplicación de la CTMF.

De esta manera, de acuerdo con el CTMF (1990), es trabajador migratorio "toda persona que vaya a realizar, realice o haya realizado una actividad remunerada en un Estado del que no sea nacional" (art. 2.1). Si se revisa de forma literal este apartado, el simple hecho de ser una persona extranjera que ingresa al territorio de otro Estado diferente al de origen en búsqueda de mejores condiciones laborales, o en virtud de un contrato acordado de forma previa al viaje, o en general en búsqueda de un trabajo que le permita su sostenibilidad, hace que se adquiera la condición de trabajador migratorio. De allí que pueda configurarse un gran grupo de personas destinatarias del marco de protección de la CMTF.

Tal como señala Rodríguez, "el catálogo de derechos de la CTMF, régimen jurídico por excelencia que regula los derechos socio-laborales en el caso de los trabajadores migrantes, se ha ido construyendo con el paso del tiempo" (2007, p.129), ha sido producto de una evolución normativa que se ha ido perfilando como un:

Régimen jurídico internacional definido por la presencia de una tendencia más o menos inclinada hacia la progresiva igualdad de trato entre el nacional y el extranjero, siempre desde el respeto al derecho soberano del Estado a fijar sus reglas de entrada, permanencia y salida de los extranjeros. (Bonet, 2003, p. 311)

La CTMF reconoce una serie de derechos de titularidad de los trabajadores migrantes sin importar su situación administrativa, es decir, si se trata de trabajadores regulares o irregulares. Así, entre los artículos 9 al 31 se condensan una serie de derechos civiles, entre los cuales se puede referir el derecho a la vida, a salir del país, a la integridad personal, a la prohibición de la esclavitud, la servidumbre y el trabajo forzoso, la libertad de expresión, de pensamiento, conciencia y religión, el derecho a la vida privada y familiar, así como el derecho a no ser privado de sus bienes, libertad y seguridad personales, garantías relacionadas con el debido proceso y el acceso a la justicia; de igual forma, la prohibición de expulsión, asistencia consular, el derecho a la personalidad jurídica y a recibir información sobre las condiciones migratorias, el derecho al nombre y a la nacionalidad, tal como lo relaciona la CTMF.

Este listado permite afirmar que se concede un marco mínimo de respeto a la dignidad y que existe, por parte del tratado internacional, un claro factor de atribución de las garantías fundado en el propio valor de la persona humana, por encima de las consideraciones asociadas a la relación con el territorio, esto es, a la nacionalidad o a la ciudadanía.

En cuanto a la protección de los derechos sociales, el catálogo es mucho más limitado (arts. 25-28); sin embargo, cobra gran importancia referirse al artículo 25 del CTMF, según el cual:

Se reconoce el derecho a un trato no menos favorable que el que reciben los nacionales en lo relacionado con las condiciones derivadas de la relación laboral. Este derecho, reviste relevancia en razón a que a través de este se evidencia cierta universalidad de los derechos de los extranjeros frente a los nacionales de un Estado. Así mismo, a los trabajadores migrantes en situación jurídica de irregularidad, se reconoce de forma específica en la CTMF el derecho a la seguridad social a fin de que, reciban el mismo trato que los nacionales en la medida en que cumplan los requisitos previstos en la legislación aplicable de ese Estado, así como el acceso a la atención médica urgente y el derecho a la educación en condiciones de igualdad con los nacionales de un Estado. (Palacios, 2012, p. 280-281)

También se garantiza a los trabajadores migratorios y a sus familiares el derecho a participar en reuniones y actividades de los sindicatos o de otras asociaciones establecidas conforme a la ley y a afiliarse libremente a estas. Este derecho a sindicalizarse y participar de las actividades de dichas organizaciones puede ser limitado en su ejercicio, pues la propia CTMF lo prevé, haciendo constar que las restricciones serán las previstas por la ley que sean necesarias en una sociedad democrática en interés de la seguridad nacional o el orden público, o bien para proteger derechos y libertades de los demás.

El reconocimiento que la CTMF establece en materia de derechos sociales es una de las principales razones por las cuales gran parte de los Estados sienten prevención a la hora de ratificarla o incorporarla a 
sus ordenamientos internos, toda vez que elevan el marco de protección. Reflejo de ello es que la CTMF, adoptada en 1990 con entrada en vigor en el 2003, cuenta a la fecha con cincuenta y dos Estados parte, de los ciento noventa y tres Estados que conforman la ONU. Esta preocupación ha sido abordada por el Comité de Protección de los Derechos de Todos los Trabajadores Migratorios y de sus Familiares, en la Observación General N. ${ }^{\circ}$ 2, en la que evidencia cómo la misma Convención no promueve una política arbitraria en materia migratoria, sino que invita a los Estados para que, en el marco de su soberanía, puedan garantizar unos mínimos de derechos a los trabajadores migrantes.

La Convención establece un equilibrio entre la facultad soberana de los Estados partes para controlar sus fronteras y regular la entrada y la permanencia de los trabajadores migratorios y sus familiares, por una parte, $y$, por otra, la protección de los derechos, enunciados en la parte III de la Convención, de todos los trabajadores migratorios y de sus familiares, incluidos los que se encuentran en situación irregular. (2013, párr.13)

Tal como señala Palacios, en virtud del análisis del artículo 88 de la CTMF:

Aquellos Estados que sean parte de este tratado deberán aceptarlo en su integridad, es decir, no podrán excluir ninguna de sus partes, las cuales son nueve. Ello refuerza el principio de no discriminación, pues la CTMF debe aplicarse a todos los trabajadores migratorios y sus familias sujetos a la jurisdicción de los Estados Parte, lo que incluye a todas las categorías de trabajadores migratorios definidos en la Convención (art. 2). Es importante tener presente que excluyen de su ámbito de aplicación a ciertas personas que no son consideradas trabajadores migratorios en los términos de este tratado (art. 3). (Palacios, 2012, p. 169)

Es innegable que la CTMF ha significado un hito en el desarrollo progresivo de los derechos y las libertades de los extranjeros pues, tal y como lo anota Cholewinski (1997, p. 201-202),

[...] la Convención es un instrumento complejo y detallado en el que su contenido es mucho más amplio o al menos protege más derechos y libertades que en los tratados de derechos humanos más clásicos que la mayoría de los países occidentales ya han ratificado.

No obstante, aún subsisten muchas de las limitaciones tradicionales en cuanto al acceso a derechos de manera universal se refiere, pues, como lo señala Vanheule (2009, p. 473),

[...] aunque una primera lectura rápida del texto podría dar la impresión de que la Convención en todos los casos trata a todos los trabajadores migrantes de la misma manera como los habitantes de los países a los que han emigrado, la realidad es mucho más sutil.

La CTMF busca promover el mejoramiento de las condiciones de vida y de trabajo de los trabajadores migratorios y sus familias, lo cual ha sido una constante preocupación de varios órganos para la conformación de tratados, tales como los informes del Comité para la Eliminación de la Discriminación Racial que, entre todas sus medidas, siempre recomienda la ratificación de la CTMF para eliminar la discriminación en contra de los extranjeros ${ }^{8}$.

\section{CONCLUSIONES}

La protección jurídica de las migraciones plantea una serie de retos a la normatividad existente. En este artículo se ofrecieron algunos análisis que ilustran sobre la importancia de que exista claridad en los conceptos y su alcance, tales como repensar la dimensión de la aplicación de los principios de igualdad y no discriminación, la universalidad de los derechos y la plenitud en su ejercicio, como es el caso de los derechos de los extranjeros, en particular de los llamados "inmigrantes económicos", sobre los cuales existe la tendencia a presumir en todos los casos su voluntariedad. Lo anterior en aras de estar en capacidad de comprender cuál es la verdadera dimensión de la igualdad en el caso particular de los migrantes económicos, para así identificar si existe o no necesidad de que se produzca un desarrollo evolutivo de estas nociones en aras de logar el mejoramiento en la garantía de los derechos.

8 A manera de ejemplo, véanse las Observaciones Finales del Comité para la Eliminación de la Discriminación Racial de 2011, pár. 18; las Observaciones Finales del Comité para la Eliminación de la Discriminación Racial de 2010, pár. 21; y las Observaciones Finales del Comité para la Eliminación de la Discriminación Racial de 2008, pár. 23, entre otros. 
En este sentido, en la actualidad la migración es bastante compleja y no resultan suficientes las respuestas que desde el derecho internacional de los derechos humanos se dan a partir de la construcción de categorías rígidas bajo las cuales se definen los movimientos de personas. En este sentido, el elemento de la voluntariedad plantea diversos interrogantes, en especial cuando el verdadero motivo por el cual una persona decide abandonar su país de origen está asociado a fenómenos tales como condiciones indignas de vida y situaciones de pobreza extrema o hambruna, escenarios en los que - por más de que se trate de razones económicas- no es dable hacer una asociación directa con la migración voluntaria. Esto terminaría por hacer exclusión de los motivos humanitarios a la hora de migrar y establecer una visión restringida de la migración.

Así las cosas, se hace indispensable el análisis de la protección de las personas migrantes desde el principio de igualdad y no discriminación, lo que permite identificar la existencia de dos problemas esenciales. Uno, derivado de la esfera de la igualdad formal, pues para los migrantes existe una limitación en el campo de aplicación personal de los tratados, lo que permite deducir una legitimación de una discriminación por un motivo prohibido, que es el origen nacional; de esto se deriva la segunda dificultad, consistente en que en consecuencia de lo anterior, las limitaciones a los derechos podrán proceder de manera discrecional y soberana por parte de los Estados, lo que también redunda de manera negativa en la igualdad material, más conocida como "real y efectiva".

Del análisis de dicho principio queda claro que este se reconoce a todas las personas conforme a lo estudiado en gran parte de los instrumentos internacionales que se han analizado, pues se emplean fórmulas que aluden a la condición humana como presupuesto para la asignación de los derechos, en función de la igualdad. Sin embargo, en algunos tratados sectoriales se permite a los Estados parte establecer diferenciaciones admisibles a la luz del derecho internacional de los derechos humanos sobre las cuales no se puede predicar discriminación (tales tratos se conocen como "distinciones").

Con lo anterior se pone en evidencia en el ejercicio de la potestad soberana de los Estados que, al configurar sus políticas migratorias, formulan restricciones a los derechos de los extranjeros y, sobre todo, de los migrantes económicos, así como el hecho de que pueden llegar a desconocer parámetros de respeto común desde una perspectiva universal de los derechos humanos. El documento busca plantear reflexiones en torno al verdadero compromiso internacional y normativo de predicar la igualdad formal y material como un atributo de todas las personas, sin que el vínculo de nacionalidad y ciudadanía sean el eje de atribución de los derechos.

La distinción, concebida como trato diferenciado legítimo, es dable a los Estados a partir de motivos objetivos, razonables y compatibles con una sociedad democrática; sin embargo, queda el cuestionamiento alrededor de cómo saber que en realidad se está frente a criterios con esas características, y que la nacionalidad no se torna en un medio para legitimar la discriminación bajo el argumento de la sostenibilidad del esquema democrático. Al parecer, la protección de grupos vulnerables ha permitido que no existan discusiones frente al reconocimiento de derechos de nacionales dentro de la jurisdicción de un Estado que requieren protección especial, sin embargo, esa condición de debilidad no parece ser suficiente en el caso de los extranjeros; por tanto, es en este punto en el que se produce una asimetría que socava el discurso de los derechos humanos. 


\section{REFERENCIAS}

Asamblea General de las Naciones Unidas. (2001). Informe, estudios y documentos a estudiar por el Comité preparatorio de la Conferencia Mundial contra el Racismo, la Discriminación Racial, la Xenofobia y las formas conexas de Intolerancia, Sra. Gabriela Rodríguez Pizarro (Doc. A/CONF.198/PC.2/23).

Asamblea General de las Naciones Unidas. (2005). Informe de la Relatora Especial sobre los Derechos Humanos de los Migrantes, Sra. Gabriela Rodríguez Pizarro, 14 de enero (E) CN.4/2005/85/Add.2).

Asamblea General de las Naciones Unidas. (2006). Diálogo de alto nivel sobre la migración internacional y el desarrollo, 13 de octubre (A/61/515).

Asamblea General de las Naciones Unidas. (2008). Informe del Relator Especial sobre el Derecho a la Alimentación, Sr. Jean Ziegler, 10 de enero (A/HRC/7/5).

Asamblea General de las Naciones Unidas. (2018). Informe del Relator Especial sobre los Derechos Humanos de los Migrantes, Sr. Felipe González Morales, 4 de mayo (A/HRC/38/41).

Asamblea General de las Naciones Unidas. (2019). Informe del Relator Especial sobre los Derechos Humanos de los Migrantes, Sr. Felipe González Morales, 15 de abril (A/HRC/41/38).

Błuś, A. (2013). Beyond the walls of paper. Undocumented migrants, the border and human rights. European Journal of Migration and Law, 15(4), 413-446.

Bonet, J. (2003). Las políticas migratorias y la protección internacional de los derechos y libertades de los inmigrantes un análisis desde la perspectiva del ordenamiento jurídico español. Bilbao: Universidad de Deusto.

Buergenthal, T., Grossman, C. y Nikken, P. (1990). Manual internacional de derechos humanos. San José de Costa Rica: Instituto Interamericano de Derechos Humanos.
Cançado Trindade, A. C. (2003). El desarraigo como problema de derechos humanos frente a la conciencia jurídica universal. En La nueva dimensión de las necesidades de protección del ser humano en el inicio del siglo XXI (2ae ed., pp. 25-82). Costa Rica: Corte Interamericana de Derechos Humanos.

Carrillo, J. A. (2001). Soberanía de los Estados y derechos humanos en derecho internacional contemporáneo (2ª ed.). Madrid: Tecnos.

Cassese, A. (1993). Los derechos humanos en el mundo contemporáneo. Barcelona: Ariel.

Chetail, V. (2013). The human rights of migrants in general international law: from minimum standards to fundamental rights. Georgetown Immigration Law Journal, 28, 225-255.

Cholewinski, R. (1997). Migrant workers in the international human rights law, their protection in countries of employment. Oxford: Claredon Press.

Chueca Sancho, A. (2003). Condición jurídica y derechos de los migrantes indocumentados: la oc-18/03 de la Corte Interamericana de Derechos Humanos. Revista de Derecho Migratorio y Extranjería, 4, 305.

Comisión de Derecho Internacional. (2006). Informe expulsión de extranjeros. Julio 10 de 2006. Doc. A/CN.4/565.

Comisión Europea contra el Racismo y la Intolerancia. (2002). Recomendación General N. ${ }^{7}$, Legislación nacional para combatir el racismo y la discriminación racial, aprobada por la ECRI, el 13 de diciembre de 2002, publicada el 17 de febrero de 2003.

Comité de Derechos Económicos, Sociales y Culturales. (2009). Observación General N. ${ }^{\circ} 20$. La no discriminación y los derechos económicos, sociales y culturales (artículo 2, párrafo 2 del Pacto Internacional de Derechos Económicos, Sociales y Culturales) (Doc. E/C.12/GC/20).

Comité de Derechos Humanos. (2008). Observación General N. ${ }^{\circ} 15$, relativa a la situación de los 
ÁREA DERECHO INTERNACIONAL Y RELACIONES INTERNACIONALES

* Análisis de la igualdad y la no discriminación en el derecho internacional de los derechos humanos: el caso de los migrantes económicos

extranjeros con arreglo al Pacto, 27 de mayo (Doc. HRI/GEN/1/Rev.9 Vol. I).

Comité de Derechos Humanos. (2008). Observación General N. ${ }^{\circ} 18$, relativa a la No discriminación, $37^{\circ}$ periodo de sesiones, 27 de mayo (Doc. HRI/GEN/1/Rev.9 Vol. I).

Comité de Protección de los Derechos de Todos los Trabajadores Migratorios y de sus Familiares. (2013). Observación General N. 2 sobre los derechos de los trabajadores migratorios en situación irregular y de sus familiares, 28 de agosto (Doc. CMW/C/GC/2).

Comité para la Eliminación de la Discriminación Racial. (2005). Recomendación General N. ${ }^{\circ}$ $\mathrm{xxx}$, Sobre la discriminación contra los no ciudadanos, $65^{\circ}$ periodo de sesiones, 27 de mayo (Doc. HRI/GEN/1/Rev. 9, Vol. II).

Comité para la Eliminación de la Discriminación Racial (2008), Observaciones Finales. Suecia, 23 de septiembre (Doc. CERD/C/SWE/CO/18).

Comité para la Eliminación de la Discriminación Racial. (2010). Observaciones Finales. Francia, 23 de septiembre (Doc. CERD/C/FRA/CO/17-19).

Comité para la Eliminación de la Discriminación Racial. (2011). Observaciones Finales. España, 8 de abril, (Doc. CERD/C/ESP/CO/18-20).

Convención Americana Sobre Derechos Humanos. (1969). Suscrita en San José de Costa Rica en la Conferencia Especializada Interamericana sobre Derechos Humanos, el 22 de noviembre de 1969.

Convención Internacional para la Eliminación de Todas las Formas de Discriminación Racial (CERD). (1965). Asamblea General de Naciones Unidas, Resolución 2106 A (xx) del 21 de diciembre 1965 en vigor: 4 de enero de 1969.

Convención Internacional sobre la protección de los derechos de todos los trabajadores migratorios y de sus familiares [CTMF]. (1990), Asamblea General de Naciones Unidas, Resolución 45/158, de 18 de diciembre de 1990, en vigor: 1 de julio de 2003 .
Convención sobre la Eliminación de todas las formas de discriminación contra la mujer [CEDAW]. (1979), Asamblea General de Naciones Unidas, Resolución 34/180, de 18 de diciembre de 1979, en vigor: 3 de septiembre de 198

Convención sobre el Estatuto de los Refugiados. (1951). Adoptada en Ginebra, Suiza, el 28 de julio de 1951 por la Conferencia de Plenipotenciarios sobre el Estatuto de los Refugiados y de los Apátridas (Naciones Unidas), convocada por la Asamblea General en su resolución 429 (V), del 14 de diciembre de 1950. Entrada en vigor: 22 de abril de 1954, de conformidad con el artículo 43. Serie Tratados de Naciones Unidas, № 2545, vol. 189.

Corte Interamericana de Derechos Humanos. (2003). Condición jurídica y derechos de los migrantes indocumentados. Opinión Consultiva N. ${ }^{\circ}$ 18 de 2003 del 17 de septiembre de 2003. Serie A, N. ${ }^{\circ} 18$.

Corte Interamericana de Derechos Humanos. (1984). Opinión Consultiva N. ${ }^{\circ} 4$ de 1984, Propuesta de Modificación a La Constitución Política de Costa Rica Relacionada con la Naturalización (N. ${ }^{\circ}$ 4, Serie A).

Courtis, C. (2006). El juego de los juristas. Ensayo de caracterización de la investigación dogmática. En C. Courtis (ed.), Observar la ley. Ensayos sobre metodología de la investigación jurídica, pp. 105-156. España: Editorial Trotta.

De Lucas, J. (2002). La herida original de las políticas de inmigración. A propósito del lugar de los derechos humanos en las políticas de inmigración. Isegoría, 26, 59-84.

De Lucas, J. (2015). Mediterráneo: el naufragio de Europa. Valencia: Tirant Humanidades.

Fernández de Casadevante Romani, C. (2007). El derecho internacional de los derechos humanos. En Derecho internacional de los derechos humanos (p. 69). Madrid: Dilex.

Declaración Americana de los Derechos y Deberes del Hombre. (1948). Novena Conferencia Internacional Americana, Bogotá, Colombia. 
Declaración Universal de los Derechos Humanos (DUDH). (1948). Proclamada por la Asamblea General de las Naciones Unidas en su resolución 217 (III) el 10 de diciembre de 1948.

Gros Espiell, H. (2007). Derechos humanos y migraciones. En Migraciones y desarrollo. II Jornadas IberoAmericanas de estudios internacionales, (pp. 37-48), realizadas en Montevideo, el 25, 26 y 27 de octubre de 2006. Madrid: Marcial Pons.

Grütters, C. A. F. M. (2011). Book review: refugees, asylum seekers and the rule of law. Comparative perspectives. En European Journal of Migration and Law, 13(2), 241-243.

International Displacement Monitoring Center y Norwegian Refugee Council. (2019). Global Report on Internal Displacement [GRID].

Juste, J. (2005). Inmigración, nacionalidad y extranjería: el marco jurídico internacional. En Estudios sobre derecho de extranjería (pp. 297-324). Instituto de Derecho Público.

Kariyawasam. (2006). La Convención de las Naciones Unidas sobre la Protección de los Derechos de Todos los Trabajadores Migratorios y de sus Familiares. En F. M. Mariño Menéndez (coord.), Un mundo sin desarraigo: el derecho internacional de las migraciones (pp. 16-28). Catarata.

Ley 387 de 1997. Por la cual se adoptan medidas para la prevención del desplazamiento forzado; la atención, protección, consolidación y esta estabilización socioeconómica de los desplazados internos por la violencia en la República de Colombia. Julio 18 de 1997. DO 43.091.

Mariño Menéndez, F. M. (1996). Los derechos de los extranjeros en el derecho internacional. En Derecho de extranjería, asilo y refugio (pp. 109126). Instituto Nacional de Servicios Sociales.

Martínez, J. (Julio-diciembre de 2011). Métodos de investigación cualitativa. Revista Silogismo, 8 (1).
OIM (Organización Internacional para las Migraciones). (2006). Glosario sobre migración. Ginebra: OIM.

Olesti Rayo, A. (2005). La inmigración irregular y el control de los flujos migratorios en la Unión Europea. En M. Vargas et al. (coords.), Soberanía del Estado y derecho internacional: homenaje al profesor Juan Antonio Carrillo Salcedo (pp. 943-964). Universidad de Córdoda, Universidad de Málaga y Universidad de Sevilla.

ONU (Organización de las Naciones Unidas). (24 de agosto de 2018). La huída de los venezolanos puede convertirse "en una crisis". Noticias ONU. Recuperado de https://news.un.org/es/ story/2018/08/1440272

ONU (Organización de las Naciones Unidas). (23 de septiembre de 2013). 232 millones de migrantes internacionales viven fuera de su país en todo el mundo, revelan las nuevas estadísticas mundiales sobre migración de las Naciones Unidas. Noticias ONU. Recuperado de 2019: http://www.un.org/es/ga/68/ meetings/migration/pdf/press_el_sept $\% 20$ 2013_spa.pdf

ONU (Organización de las Naciones Unidas). (26 de junio de 1945). Carta de las Naciones Unidas. San Francisco.

Palacios, M. T. (2012a). La vida digna en el contexto de la inmigración: los trabajadores migratorios (Tesis doctoral sin publicación). Facultad de Derecho, Universidad de Sevilla, Sevilla, España. Recuperado de https://idus.us.es/ xmlui/bitstream/handle/11441/74006/Tesis_Palacios\%20Sanabria\%2C\%20M.\%20 Teresa.pdf?sequence $=1 \&$ isAllowed $=y$

Palacios, M. T. (2012b). La aplicación del principio de igualdad y no discriminación a los trabajadores migratorios, pp. 77-92. Civilizar. Ciencias Sociales y Humanas, 12(22).

Pureza, J. M. (2004). La protección internacional de los derechos humanos en los albores del siglo XXI. Bilbao: Universidad de Deusto. 
ÁREA DERECHO INTERNACIONAL Y RELACIONES INTERNACIONALES

* Análisis de la igualdad y la no discriminación en el derecho internacional de los derechos humanos: el caso de los migrantes económicos

Rodríguez, C. (2007). Análisis crítico de la normativa internacional de protección de los trabajadores migrantes: el papel de la OाT. En Migraciones y desarrollo: II Jornadas Iberoamericanas de Estudios Internacionales (pp. 127-136), realizadas en Montevideo, el 25, 26 y 27 de octubre de 2006. Marcial Pons.

Sandoval, C. A. (1996). Investigación cualitativa. Bogotá: Instituto Colombiano para el Fomento de la Educación Superior.

Sicremi (Sistema Continuo de Reportes sobre Migración Internacional en las Américas). (2017). Cuarto Informe del Sistema Continuo de Reportes sobre Migración Internacional en las Américas. OEA, OCDE. Recuperado de http:// www.oas.org/documents/spa/press/SICREMI2017-espanol-web-FINAL.pdf

Tribunal Europeo de Derechos Humanos. Gaygusuz C. Austria, N. ${ }^{\circ}$ (A. 1996/40) (16 de septiembre de 1996).

Vanheule, D. (2009). The International Convention on the Protection of the rights of All Migrant
Workers and Members of their Families. En F. Gómez Isa y K. de Feyter (eds.), International Human Rights Law in a Global Context (p. 473). Bilbao: University of Deusto.

Varlez, L. (1929). Les migrations internationales et leur règlementation. Acadèmie de Droit International, 20, 169-344.

Varona Martínez, G. (1994). La inmigración irregular derechos y deberes humanos. Guipúzcoa: Ararteko.

Villar, P. A. (2005). El fenómeno de la inmigración en Europa, perspectivas jurídicas y económicas. Madrid: Dykinson.

Villán, C. (2001). La Declaración Universal de Derechos Humanos en la práctica de las Naciones Unidas. En A. Blanc (ed.), La protección internacional de los derechos humanos a los cincuenta años de la Declaración Universal (pp. 51-62). Madrid: Tecnos. 